\title{
Suplementação Energética sobre a Qualidade da Carcaça e da Carne de Vacas de Diferentes Idades, Terminadas em Pastagem Cultivada de Estação Fria sob Pastejo Horário
}

\section{Fabiano Nunes Vaz ${ }^{1}$, João Restle ${ }^{2}$, Ivan Luiz Brondani ${ }^{3}$, Eduardo Castro da Costa ${ }^{4}$, Ricardo Zambarda Vaz $^{5}$, Cledson Roso ${ }^{6}$, Charles de Oliveira Carrilho ${ }^{7}$}

\begin{abstract}
RESUMO - O objetivo deste trabalho foi estudar diferentes níveis de suplementação energética sobre a qualidade da carcaça e da carne de vacas de descarte, de diferentes idades, terminadas no sistema de pastejo horário sobre azevém (Lolium multiflorum) mais triticale (Xtriticosecale). Foram utilizadas 40 vacas de descarte Charolês, agrupadas em quatro classes, em função da idade ao abate: quatro, cinco ou seis, sete ou oito e nove ou mais anos de idade, distribuídas ao acaso em quatro níveis de suplementação energética (NS): $0 ; 0,3 ; 0,6$; e $0,9 \%$ do peso vivo. O grão de sorgo triturado foi o suplemento utilizado. Não houve interação significativa entre nível de suplemento e idade do animal. O nível de suplementação utilizado não afetou as características cor, textura e marmoreio da carne, assim como a composição física da carcaça, características sensoriais da carne e quebras ao descongelamento e à cocção. Com o aumento da idade, decresceu a porcentagem de músculo na carcaça, sendo de 68,5;66,7;65,1; e 64,3\%, respectivamente. As vacas mais jovens apresentaram menor porcentagem de gordura $(14,4 \%)$ do que os animais mais velhos, que apresentaram 17,$9 ; 19,2 ;$ e $18,7 \%$ para idade ao abate de cinco ou seis, sete ou oito e nove ou mais anos, respectivamente. As vacas mais jovens apresentaram menor relação músculo + gordura / osso do que as abatidas com idade intermediária. As vacas abatidas aos quatro anos apresentaram carne mais macia (5,92 pontos) que vacas abatidas aos sete ou oito anos de idade (4,69 pontos).
\end{abstract}

Palavras-chave: Charolês, composição da carcaça, maciez, marmoreio, vacas de descarte

\section{Energetic Supplementation on Carcass and Meat Quality of Cull Cows of Different Ages, Finished on Cultivated Winter Pasture Under Temporary Grazing}

\begin{abstract}
The objective of this experiment was to study different levels of energy supplementation on the carcass and meat qualitative characteristics of beef cull cows of different ages, under temporary grazing on cultivated pasture of ryegrass (Lolium multiflorum) plus triticale (Xtriticosecale). Fourty Charolais cows were divided into four age classes: four, five or six, seven or eight and nine or more years, and randomly alloted to four levels of supplementation (SL): 0, .3, .6 and .9\% of live weight. The supplement used was grounded sorghum grain. No significant interaction was observed between supplementation level and cow age. SL did not affect meat color, texture and marbling, neither carcass physical composition, meat sensorial characteristics and thawing and cooking losses. With age increasing, decreased the muscle percentage, being 68.5, 66.7, 65.1 and 64.3\%, respectively. Young cows showed lower fat percentage (14.4\%) than the older animals, that showed 17.9, 19.2 and 18.7\%, respectively, for five or six, seven or eigth, and nine or more years of age. Young cows showed lower muscle + fat / bone relation than the animals slaughtered with intermediate age. Cows slaughtered at four years showed more tender meat (5.92 points) than cows slaughtered at seven or eigth (4.69 points) years of age.
\end{abstract}

Key Words: carcass composition, Charolais, cull cows, marbling, tenderness

\section{Introdução}

Segundo as estatísticas apresentadas no ANUALPEC (2000), o abate de fêmeas bovinas vem ganhando importância expressiva na carne comercializada nos mercados brasileiros, fatoquetambém acontece em outros países. No entanto, em outras nações, as fêmeas abatidas são, na maioria, de raças leiteiras, motivo principal da baixa valorização que recebem, pois raças leiteiras apresentam carcaças com maior porcentagem de ossos, baixo rendimento de carcaça e carne menos macia que as raças de corte (Vaz \& Restle, 1998).

\footnotetext{
1 Zootecnista, MS, Progepec Consultores Associados Ltda. Rua Benjamin Constant, 930/313, CEP 97050 020, Santa Maria - RS. E.mail: fnvaz@terra.com.br

2 Engenheiro-Agrônomo, PhD, Professor Titular do Departamento de Zootecnia-UFSM, Pesquisador do CNPq-Campus de Camobi, CEP 97105 900, Santa Maria, RS. E.mail: jorestle@ccr.ufsm.br

3 Zootecnista, Ms, Prof. UFSM, Aluno de Doutorado UNESP-Jaboticabal, SP.

4 Zootecnista, Aluno do curso de Mestrado em Zootecnia-UFSM.

5 Engenheiro-Agrônomo, Progepec Consultores Associados LTDA. E.mail: progepec@terra.com.br

6 Zootecnista, Ms, Progepec Consultores Associados LTDA. E.mail: progepec@terra.com.br

7 Aluno do curso de Zootecnia-UFSM, Bolsista IC-FAPERGS.
} 
Todavia, no Brasil, grande parte das fêmeas abatidas pertence a raças de corte, porém também é pouco valorizada pelos abatedouros. Esse fato se torna preocupante, à medida que essa categoria é responsável por grande parte da renda do pecuarista de corte brasileiro, por ser um subproduto dos sistemas de ciclo completo e muito utilizada pelos invernadores do sul do país para terminação em pastagens cultivadas, alcançando bons ganhos de peso e proporcionando terminação rápida (Restle et al., 1998).

Além disso, a melhoria dos índices de produtividade da pecuária de corte brasileira tem produzido um excedente de novilhas, as quais podem ser terminadas visando obter carne de qualidade comparável à de novilhos. Comparando vacas e novilhas, Kropf \& Graf (1959) verificaram que a porcentagem de gordura foi superior nas novilhas e a de músculo, maior nas vacas de descarte. Estudando as características de carcaça de vacas ou novilhas de corte terminadas em confinamento, Restle et al. (2000c) verificaram maior rendimento de carcaça e porcentagem de serrote nas novilhas.

Ao relacionar várias alternativas para a melhoria dos índices produtivos e econômicos da pecuária de corte, Restle (1999) cita como um dos mais rentáveis o uso da suplementação em pastagem cultivada, associada ou não, ao sistema de pastejo horário. Segundo Pascoal et al. (1999), o uso da suplementação energética em pastagens de estação fria, no sistema de pastejo horário, proporciona melhor aproveitamento da grande quantidade de proteína produzida pelas forrageiras de inverno utilizadas, propiciando maior ganho de peso diário por animal.

Embora a suplementação em pastagem cultivada já seja bem aceita nos sistemas de terminação, restam dúvidas sobre os efeitos da suplementação, ou dos níveis utilizados, sobre as características finais dos produtos, principalmente, quando se trata de vacas ou novilhas de descarte. Este trabalho foi conduzido com o objetivo de estudar o efeito da idade ao abate sobre as características qualitativas da carcaça e da carne de vacas de descarte Charolês, terminadas com suplementação energética com grão de sorgo moído, em pastagem cultivada de azevém (Lolium multiflorum) + triticale ( $X$ triticosecale) associada ao sistema de pastejo horário.

\section{Material e Métodos}

O trabalho de campo foi conduzido nas dependências do Setor de Bovinocultura de Corte, e as análises da carne foram realizadas no Laboratório de Carnes do Departamento de Zootecnia da Universidade Federal de Santa Maria, RS.

O trabalho de campo foi conduzido no período de junho a agosto de 1997, quando ocorreu a terminação de 40 vacas de descarte Charolês, agrupadas em quatro classes de idades: animais de quatro anos (IA4), cinco ou seis anos (IA5-6), sete ou oito anos (IA7-8) e animais com nove e mais anos de idade (IA+8). Durante a terminação, as vacas de cada classe de idade foram distribuídas ao acaso em quatro níveis de suplementação energética (NS): 0;0,3;0,6; e 0,9\% de matéria seca em relação ao peso vivo dos animais.

A terminação das vacas foi realizada sobre pastagem de azevém (Lolium multiflorum) + triticale (X triticosecale), no sistema de pastejo horário. Os animais pastejaram a mesma área, sendo empregado o sistema de pastejo horário, dividido em dois períodos de pastejo: pela parte da manhã, das 8 às $10 \mathrm{~h}$, e pela parte da tarde, das 16 às $18 \mathrm{~h}$. Para manter uma massa de forragem disponível próximo a $1.300 \mathrm{~kg}$ de MS por hectare, a lotação foi variável, utilizando-se a técnica put and take (Mott \& Lucas, 1952).

O grão de sorgo triturado foi o suplemento utilizado, sendo fornecido em cochos de madeira, com acesso de 1,05 m por animal. A analise bromatológica do sorgo apontou $88,0 \%$ de matéria seca (MS), 9,19\% de proteína bruta e $84,0 \%$ de NDT na MS. O suplemento foi dividido em duas partes, fornecido pela manhã e pela tarde, sempre após os períodos de pastejo; para isso, foi realizada a separação dos animais nos quatro lotes (níveis de suplementação). No intervalo dos períodos de pastejo, os animais ficavam em uma área de 1,5 ha de campo nativo, onde tinham água de boa qualidade e sal comum à vontade.

$\mathrm{O}$ abate dos animais ocorreu conforme o fluxo normal do frigorífico, sendo que as carcaças foram identificadas, lavadas e levadas ao resfriamento por 24 horas, a $-2^{\circ} \mathrm{C}$. Após esse tempo, realizou-se o corte da carcaça esquerda na altura da $12^{\mathrm{a}}$ costela, onde, após a exposição do músculo Longissimus dorsi por 20 minutos, para oxigenação da mioglobina, foram avaliadas as características cor e textura da carne, segundo uma escala de cinco pontos, e o marmoreio da carne, classificado numa escala de 18 pontos (Muller, 1987). 
Após essas medidas, foi retirada da carcaça

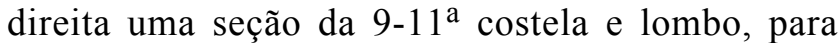
determinação da composição física da carcaça, conforme a metodologia que sugeriram Hankins \& Howe (1946). Depois da realização dessa técnica, a porção do músculo Longissimus dorsi removida dessa amostra foi embalada, identificada e levada para congelamento no Laboratório de Carnes.

A partir do músculo congelado, foram extraídas duas fatias de 2,5 cm de espessura, obtidas perpendicularmente ao comprimento do músculo, as quais foram usadas para avaliação da quebra ao descongelamento, à cocção e resistência das fibras ao corte (fatia $\mathrm{B}$ ) e avaliação das características sensoriais (fatia A).

Para realizar o cálculo das perdas ao descongelamento e cocção, foi feita a pesagem da fatia $\mathrm{B}$, ainda congelada, depois de descongelada (antes de ser levada ao forno) e após o cozimento, que aconteceu até que a temperatura interna da fatia atingisse $70^{\circ} \mathrm{C}$. A pesagem após o cozimento da fatia foi realizada depois que esta voltou à temperatura ambiente.

Depois do cozimento e pesagem da fatia, foram retiradas três amostras de feixes de fibras, circulares, com $1 \mathrm{~cm}^{2}$ de área, as quais foram cortadas perpendicularmente à fibra, por intermédio do aparelho WarnerBratzler Shear. Para obter a medida, calculou-se a média aritmética de seis leituras (duas por amostra).

As características sensoriais da carne foram avaliadas após a cocção das fatias de músculo, em que foi distribuída uma porção de $1 \mathrm{~cm}^{3}$, da fatia $\mathrm{A}$, para cada um dos avaliadores, os quais foram previamente treinados para atribuir valores de 1 a 9 para as características maciez, suculência e palatabilidade da carne. Para as três características, os valores aumentam conforme melhora os atributos da carne, ou seja, mais macia, saborosa ou suculenta.

O delineamento experimental foi o inteiramente casualizado. Os dados foram analisados pelo método dos quadrados mínimos (SAS, 1990), utilizando-se o seguinte modelo estatístico:

$$
\mathrm{Y}_{\mathrm{ij}}=\mu+\mathrm{NS}_{\mathrm{i}}+\mathrm{IA}_{\mathrm{j}}+\mathrm{e}_{\mathrm{ij}}
$$

em que: $Y_{i j}$ representa a observação realizada no nésimo animal, pertencente ao i-ésimo nível de suplementação e j-ésima idade; $\mu$, a média geral da característica; $\mathrm{NS}_{\mathrm{i}}$, o i-ésimo nível de suplementação energética; $\mathrm{IA}_{\mathrm{j}}$, a j-ésima idade do animal; $\mathrm{e}_{\mathrm{ij}}$, o efeito residual.

A interação entre nível de suplementação e idade do animal foi inicialmente testada e removida do modelo final, por não ter sido significativa em nenhu- ma variável dependente. Os dados coletados para nível de suplementação também foram submetidos à análise de regressão polinomial, por intermédio do procedimento "proc reg" do programa SAS (1990).

\section{Resultados e Discussão}

$\mathrm{Na}$ Tabela 1 são apresentados os resultados resumidos da análise de variância dos dois efeitos estudados, idade da vaca e nível de suplementação energética, durante a terminação em pastagem cultivada.

Constam da Tabela 2 os resultados referentes às características cor, textura e marmoreio, e composição física da carcaça em função do nível de suplementação energética utilizada. Observa-se que não existiu diferença $(\mathrm{P}>0,5)$ para cor, textura e marmoreio da carne, sendo que os tratamentos apresentaram carne de coloração classificada como "vermelha levemente escura" ou "vermelha", textura "média" ou "fina" e marmoreio "leve menos" ou "leve típico".

Restle et al. (2001b) constataram que vacas de descarte não-suplementadas apresentaram marmoreio classificado como "leve menos", ficando as vacas suplementadas com 0,4 ou $0,8 \%$ do peso vivo, com marmoreio classificado como "leve mais", sendo que a análise de regressão mostrou que a textura da carne ficou mais grosseira, à medida que aumentou o nível de suplementação. Com níveis de concentrado variando entre 0 e $60 \%$ na dieta de animais Nelore confinados, Feijó et al. (1996a) não observaram efeito na cor e textura da carne, porém verificaram maior marmoreio na carne com níveis mais baixos de concentrado, não verificando diferença nessas três variáveis quando esses níveis foram oferecidos para animais $F_{1}$ Pardo Suíço x Nelore (Feijó et al., 1996b).

Na Tabela 2, constata-se também que a composição física da carcaça não foi alterada pelo nível de suplemento energético empregado, sendo que o percentual de gordura variou de $16,54 \%$ nas vacas não-suplementadas a $18,51 \%$ nas vacas suplementadas com $0,9 \%$ do peso vivo. Berg \& Butterfield (1976) afirmam que, com peso de abate semelhante, não são esperadas diferenças na composição corporal de animais que passam por crescimento compensatório durante a terminação. Trabalhando com novilhos cruzados Pardo Suiço x Nelore, Feijó et al. (1996b) observaram que os teores de músculo, osso e gordura da carcaça permaneceram inalterados frente a variação dos níveis de concentrado entre $0 \mathrm{e}$ 
Tabela 1 - Quadrados médios das análises de variância e teste F, para a qualidade da carcaça e da carne de vacas de descarte de diferentes idades terminadas com diferentes níveis de suplementação energética

Table 1 - Mean squares of the analysis of variance and $F$ test, for carcass and meat quality of cull cows of different ages finished with different energy supplementation levels

\begin{tabular}{|c|c|c|c|c|c|c|c|}
\hline \multirow[b]{2}{*}{$\begin{array}{l}\text { Característica } \\
\text { Characteristic }\end{array}$} & \multicolumn{3}{|c|}{$\begin{array}{l}\text { Graus de liberdade } \\
\text { Degrees of freedom }\end{array}$} & \multicolumn{3}{|c|}{$\begin{array}{l}\text { Quadrado médio } \\
\text { Means squares }\end{array}$} & \multirow[t]{2}{*}{$\begin{array}{c}\mathrm{R}^{2} \\
R \text {-square }\end{array}$} \\
\hline & $\mathrm{NS}^{1}$ & $\begin{array}{l}\text { Idade } \\
\text { Age }\end{array}$ & $\begin{array}{l}\text { Erro } \\
\text { Error }\end{array}$ & $\mathrm{NS}^{1}$ & $\begin{array}{c}\text { Idade } \\
\text { Age }\end{array}$ & $\begin{array}{l}\text { Erro } \\
\text { Error }\end{array}$ & \\
\hline $\begin{array}{l}\text { Cor } \\
\text { Meat color }\end{array}$ & 3 & 3 & 33 & 0,750 & 0,249 & 0,605 & 0,12 \\
\hline $\begin{array}{l}\text { Textura } \\
\text { Texture }\end{array}$ & 3 & 3 & 33 & 0,370 & 0,521 & 0,862 & 0,09 \\
\hline $\begin{array}{l}\text { Marmoreio } \\
\text { Marbling }\end{array}$ & 3 & 3 & 33 & 2,56 & 3,33 & 3,75 & 0,13 \\
\hline $\begin{array}{l}\text { Porcentagem de músculo } \\
\text { Muscle percentage }\end{array}$ & 3 & 3 & 33 & 5,4 & $42,0 * *$ & 7,9 & 0,36 \\
\hline $\begin{array}{l}\text { Porcentagem de osso } \\
\text { Bone percentage }\end{array}$ & 3 & 3 & 33 & 0,67 & $4,89 * *$ & 0,96 & 0,36 \\
\hline $\begin{array}{l}\text { Porcentagem de gordura } \\
\text { Fatpercentage }\end{array}$ & 3 & 3 & 33 & 7,7 & $64,1 * *$ & 7,3 & 0,49 \\
\hline $\begin{array}{l}\text { Relação músculo/osso } \\
\text { Muscle/bone relation }\end{array}$ & 3 & 3 & 33 & 0,048 & $0,250^{+}$ & 0,110 & 0,20 \\
\hline $\begin{array}{l}\text { Rel. músc.+gordura/osso } \\
\text { Muscle+fat/bone relation }\end{array}$ & 3 & 3 & 33 & 0,102 & $0,781^{*}$ & 0,160 & 0,35 \\
\hline $\begin{array}{l}\text { Maciez } \\
\text { Tenderness }\end{array}$ & 3 & 3 & 33 & 0,537 & $2,943 *$ & 0,927 & 0,25 \\
\hline $\begin{array}{l}\text { Suculência } \\
\text { Juiciness }\end{array}$ & 3 & 3 & 33 & 0,700 & 0,154 & 1,022 & 0,07 \\
\hline $\begin{array}{l}\text { Palatabilidade } \\
\text { Flavor }\end{array}$ & 3 & 3 & 33 & 0,730 & 0,563 & 0,522 & 0,18 \\
\hline $\begin{array}{l}\text { Força de cizalhamento } \\
\text { Shear force }\end{array}$ & 3 & 3 & 33 & 1,921 & 1,657 & 2,280 & 0,12 \\
\hline $\begin{array}{l}\text { Quebra descongelamento } \\
\text { Thawing loss }\end{array}$ & 3 & 3 & 33 & 16,3 & 40,6 & 24,8 & 0,17 \\
\hline $\begin{array}{l}\text { Quebra à cocção } \\
\text { Cooking loss }\end{array}$ & 3 & 3 & 33 & 62,9 & 52,2 & 56,1 & 0,16 \\
\hline
\end{tabular}

$60 \%$ da dieta oferecida no confinamento. Estudando novilhos abatidos aos 24 meses de idade, Restle et al. (2000a) verificaram que não existiu diferença na composição física da carcaça, frente aos níveis de concentrado equivalentes a 0,$6 ; 0,9$; e $1,2 \%$ do peso vivo. Em animais Nelore (Euclides Filho et al., 1997) ou mestiços (Zervoudakis et al., 2000), também verificou-se que o aumento no nível de suplementação não afetou a composição física da carcaça.

Segundo Restle et al. (2001b), quando se trabalha com terminação de vacas, pode-se esperar que o ganho de peso seja, em parte, constituído por recuperação de estado corporal, sendo um fenômeno que pode ser considerado como ganho de peso compensatório. Di Marco (1994) relatou que animais adultos já possuem crescimento ósseo definido, ocorrendo, então, ganho de peso através do preenchimento corporal com tecidos musculares e adiposos, sendo que as variações de composição do ganho de peso serão afetadas pelo tipo biológico do animal em questão.

Sem dúvida, entre as raças mais exploradas no Brasil, atualmente, a Charolesa é uma das mais tardias em deposição de gordura, conforme tem sido demonstrado em vários trabalhos (Perobelli et al., 1994; Restle et al., 1996; Rocha et al., 1997; Vaz, 1999).

Verifica-se, na Tabela 3, que os resultados referentes à suculência e palatabilidade da carne foram similares entre os tratamentos $(\mathrm{P}>0,05)$, assim como 
Tabela 2 - Média e desvio-padrão para cor, textura, marmoreio e composição física da carcaça de vacas de descarte terminadas com diferentes níveis de suplementação energética em pastagem cultivada de estação fria sob pastejo horário

Table 2 - Mean and standard deviation for meat color, texture, marbling and physical composition of the carcass of cull cows finished with different energy supplementation levels on cultivated winter pasture under temporary grazing

\begin{tabular}{|c|c|c|c|c|c|}
\hline \multirow[t]{2}{*}{$\begin{array}{l}\text { Característica } \\
\text { Characteristic }\end{array}$} & \multicolumn{4}{|c|}{$\begin{array}{l}\text { Nível de suplementação (em \% do peso vivo) } \\
\text { Supplementation level (in \% of live weight) }\end{array}$} & \multirow[t]{2}{*}{$\mathrm{P}^{4}$} \\
\hline & NS0 & NS03 & NS06 & NS09 & \\
\hline $\begin{array}{l}\text { Cor, pontos }{ }^{1} \\
\text { Meat color, points } 1\end{array}$ & $4,37+0,29$ & $3,95+0,35$ & $3,71+0,28$ & $3,65+0,31$ & 0,31 \\
\hline $\begin{array}{l}\text { Textura, pontos } \\
\text { Texture, points }\end{array}$ & $3,12+0,33$ & $3,43+0,39$ & $3,00+0,32$ & $2,87+0,36$ & 0,73 \\
\hline $\begin{array}{l}\text { Marmoreio, pontos } \\
\text { Marbling, points } \\
3\end{array}$ & $4,25+0,67$ & $4,75+0,80$ & $5,29+0,65$ & $4,83+0,73$ & 0,57 \\
\hline $\begin{array}{l}\text { Porcentagem de músculo } \\
\text { Muscle percentage }\end{array}$ & $67,2+1,0$ & $66,0+1,2$ & $65,8+1,0$ & $65,7+1,1$ & 0,57 \\
\hline $\begin{array}{l}\text { Porcentagem de osso } \\
\text { Bone percentage }\end{array}$ & $16,4+0,3$ & $16,9+0,4$ & $16,2+0,3$ & $15,9+0,4$ & 0,56 \\
\hline $\begin{array}{l}\text { Porcentagem de gordura } \\
\text { Fatpercentage }\end{array}$ & $16,54+1,0$ & $17,05+1,2$ & $18,11+1,0$ & $18,51+1,1$ & 0,38 \\
\hline $\begin{array}{l}\text { Relação músculo / osso } \\
\text { Muscle / bone relation }\end{array}$ & $4,15+0,11$ & $3,92+0,13$ & $4,07+0,10$ & $4,13+0,12$ & 0,73 \\
\hline $\begin{array}{l}\text { Rel. músc. }+ \text { gordura / osso } \\
\text { Muscle+fat/bone relation }\end{array}$ & $5,18+0,13$ & $4,93+0,16$ & $5,20+0,13$ & $5,30+0,14$ & 0,60 \\
\hline
\end{tabular}

${ }^{1}$ Escala de 1 a 5 pontos, sendo $3=$ vermelha levemente escura e $4=$ vermelha.

2 Escala de 1 a 5 pontos, sendo $2=$ grosseira, $3=$ levemente grosseira e $4=$ fina.

3 Escala de 1 a 18 pontos, sendo $4=$ leve menos, $5=$ leve e $6=$ leve mais.

4 Probabilidade.

1 Score from 1 to 5 points, being $3=$ slight dark red and $4=$ red.

2 Score from 1 to 5 points, being $2=$ coarse, $3=$ slightly coarse and $4=$ fine.

3 Score from 1 to 18 points, being $4=$ slight minus, $5=$ slight and $6=$ slight plus.

4 Probability.

na maciez e na medida da força necessária para o cizalhamento das fibras. Crouse et al. (1986) afirmam que diferenças na maciez da carne podem ser esperadas, quando os animais possuem diferença no ganho de peso durante a terminação, pois o rápido crescimento muscular propicia a formação de colágeno de maior solubilidade. Dessa forma, como não foi observada diferença no ganho de peso dos animais durante a terminação (Restle et al., 2000b), pode-se esperar que as características relacionadas à maciez da carne se manifestem de forma similar entre os tratamentos estudados.

Também trabalhando com vacas de descarte, Feijó et al. (2000) verificaram que o aumento no nível de concentrado utilizado em confinamento melhorou a palatabilidade da carne, sendo a mesma de 5,$9 ; 6,1$; e 6,4 pontos, respectivamente, para os níveis de concentrado de $0 ; 0,5 ; \mathrm{e} 1 \%$ do peso vivo, entretanto, as características maciez da carne e força de cizalhamento não foram afetadas pelo nível de concentrado utilizado. Esses mesmos autores comentaram que as semelhanças na maciez da carne e suculência devem-se ao fato de o ponto de abate dos animais ter sido determinado pelo grau de acabamento dos mesmos e, portanto, resultados diferentes poderiam ser esperados, quando o peso vivo determinasse o ponto de abate.

Os resultados referentes às quebras ao descongelamento e à cocção da carne (Tabela 3) mostram que também não existiu diferença nessas características. Estudando novilhos terminados com diferentes porcentagens de concentrado na dieta em confinamento, Pascoal et al. (1998) verificaram que as quebras ao descongelamento e à cocção não foram afetadas pelo nível de concentrado utilizado.

Os resultados referentes à cor, textura e marmoreio da carne, em função da idade ao abate, são apresentados na Tabela 4. Observa-se que a variação na idade dos animais não afetou a coloração da carne e a textura. Berg \& Butterfield (1976) e Muller (1987) afirmam que animais mais velhos são propensos a mostrar carne de coloração mais escura e textura mais grosseira. No presente trabalho, também o grau de marmorização da carne foi similar $(\mathrm{P}>0,05)$ entre as classes de idade avaliadas. 
Tabela 3 - Média e desvio-padrão para características sensoriais, força de cizalhamento e quebras durante o descongelamento e cocção da carne de vacas de descarte terminadas com diferentes níveis de suplementação energética em pastagem cultivada de estação fria sob pastejo horário

Table 3 - Mean and standard deviation for sensorial characteristics, shear force and losses during thawing and cooking of meat of cull cows finished with different energy supplementation levels on cultivated winter pasture under temporary grazing

\begin{tabular}{|c|c|c|c|c|c|}
\hline \multirow[t]{2}{*}{$\begin{array}{l}\text { Característica } \\
\text { Characteristic }\end{array}$} & \multicolumn{4}{|c|}{$\begin{array}{l}\text { Nível de suplementação (em \% do PV) } \\
\text { Supplementation level (in \% of live weight) }\end{array}$} & \multirow[t]{2}{*}{$\mathrm{P}^{2}$} \\
\hline & NS0 & $\mathrm{NS} 03$ & NS06 & NS09 & \\
\hline $\begin{array}{l}\text { Maciez, pontos } 1 \\
\text { Tenderness, points } 1\end{array}$ & $5,62+0,37$ & $4,96+0,34$ & $5,18+0,34$ & $5,46+0,36$ & 0,66 \\
\hline $\begin{array}{l}\text { Suculência, pontos }{ }^{1} \\
\text { Juiciness, points } 1\end{array}$ & $6,32+0,29$ & $5,65+0,26$ & $5,86+0,26$ & $5,94+0,28$ & 0,64 \\
\hline $\begin{array}{l}\text { Palatabilidade, pontos }{ }^{1} \\
\text { Flavor, points } 1\end{array}$ & $6,08+0,42$ & $5,70+0,38$ & $5,60+0,38$ & $6,11+0,40$ & 0,32 \\
\hline $\begin{array}{l}\text { Força de cizalhamento, } \mathrm{kg} \\
\text { Shear force, } \mathrm{kg}\end{array}$ & $6,20+0,57$ & $6,40+0,52$ & $5,82+0,51$ & $5,52+0,55$ & 0,49 \\
\hline $\begin{array}{l}\text { Quebra descongelamento, \% } \\
\text { Thawing loss, \% }\end{array}$ & $6,81+2,01$ & $7,51+1,83$ & $8,95+1,81$ & $6,95+1,93$ & 0,64 \\
\hline $\begin{array}{l}\text { Quebra à cocção, \% } \\
\text { Cooking loss, \% }\end{array}$ & $30,9+2,8$ & $27,7+2,6$ & $26,8+2,6$ & $26,4+2,7$ & 0,37 \\
\hline
\end{tabular}

Comparando novilhos de 2,5 anos e vacas de descarte das raças Charolês e Devon, Muller et al. (1984) verificaram carne de coloração mais escura e textura mais grosseira nos animais mais velhos. Trabalhando com as mesmas categorias de bovinos, Townsend et al. (1990b) verificaram que a coloração foi mais clara nos novilhos, sendo classificada como vermelha brilhante, enquanto as vacas apresentaram carne vermelha levemente escura. Estudando novilhas ou vacas de descarte Charolês, Restle et al. (2001a) observaram que a textura da carne foi mais fina nas fêmeas mais jovens (3,67 contra 2,89 pontos).

Observa-se, na Tabela 4, que o marmoreio da carne foi similar entre os quatro grupos de idade estudados $(\mathrm{P}>0,05)$, sendo classificado como "leve menos" nas vacas de quatro ou sete e oito anos, "leve" nas vacas com mais de oito anos e "leve mais" nas vacas com cinco ou seis anos. Já Muller et al. (1984), estudando novilhos e vacas, observaram marmoreio maior nos animais mais velhos (pequeno) em relação aos jovens (leve). Muller \& Primo (1986) comentam que animais abatidos com idades mais avançadas podem apresentar maiores ou menores quantidades de marmoreio na carne, conforme as carências alimentares por que o animal passou durante a vida, já que a gordura de marmoreio é a primeira a ser mobilizada para o fornecimento de energia ao animal, nos períodos de carência. Townsend et al. (1990b) verificaram marmoreio semelhante entre novilhos de 2,5 anos e vacas de descarte.

Restle et al. (2001a) observaram que o marmoreio foi menor em novilhas ( 6,40 pontos $)$ em relação às vacas de descarte $(8,72$ pontos $)$. Já no presente trabalho, a diferença entre a deposição de gordura entre vacas jovens e vacas mais velhas foi observada na percentagem de gordura na carcaça. A menor porcentagem de gordura na carcaça das vacas abatidas aos quatro anos foi compensada por maior percentual de músculo e de osso na carcaça $(\mathrm{P}<0,05)$. A porcentagem de ossos mais alta nas carcaças das vacas de quatro anos do que em vacas abatidas com idade intermediária foi responsável pela menor relação músculo + gordura / osso na carcaça das vacas abatidas aos quatro anos. Del Duca et al. (1999) verificaram que o incremento do peso de abate de animais Ibajé de 380 para $540 \mathrm{~kg}$ acarretou aumento da idade ao abate em 1,5 ano. Após o abate e avaliação da carcaça, esses autores verificaram que os animais mais leves e mais jovens apresentaram menores valores para a relação músculo + gordura/osso.

Comparando animais que apresentaram idade variando entre dois e quatro anos ao abate, Muller \& Primo (1986) verificaram maior percentual de músculo nos animais abatidos com menor idade, ressal- 
Tabela 4 - Média e desvio-padrão para cor, textura, marmoreio e composição física da carcaça de vacas de descarte de diferentes idades de abate (IA)

Table 4 - Mean and standard deviation for meat color, texture, marbling and physical composition of the carcass of cull cows of different slaughter ages (IA)

\begin{tabular}{|c|c|c|c|c|c|}
\hline \multirow[t]{2}{*}{$\begin{array}{l}\text { Característica } \\
\text { Characteristic }\end{array}$} & \multicolumn{4}{|c|}{$\begin{array}{c}\text { Idade da vaca (anos) } \\
\text { Cow age (years) }\end{array}$} & \multirow[t]{2}{*}{$\mathrm{P}^{4}$} \\
\hline & IA4 & IA5-6 & IA7-8 & $\mathrm{IA}+8$ & \\
\hline $\begin{array}{l}\text { Cor, pontos } 1 \\
\text { Meat color, points } 1\end{array}$ & $3,80+0,22$ & $3,87+0,34$ & $4,12+0,27$ & $3,87+0,37$ & 0,75 \\
\hline $\begin{array}{l}\text { Textura, pontos } \\
\text { Texture, points }\end{array}$ & $3,22+0,25$ & $3,50+0,39$ & $2,96+0,30$ & $2,75+0,42$ & 0,61 \\
\hline $\begin{array}{l}\text { Marmoreio, pontos } \\
\text { Marbling, points }{ }^{3}\end{array}$ & $4,33+0,51$ & $5,75+0,80$ & $4,42+0,62$ & $4,62+0,87$ & 0,46 \\
\hline $\begin{array}{l}\text { Porcentagem de músculo } \\
\text { Muscle percentage }\end{array}$ & $68,5+0,8^{\mathrm{a}}$ & $66,7+1,2^{\mathrm{ab}}$ & $65,1+0,9^{b}$ & $64,3+1,3^{b}$ & 0,01 \\
\hline $\begin{array}{l}\text { Porcentagem de osso } \\
\text { Bonepercentage }\end{array}$ & $17,1+0,3^{\mathrm{a}}$ & $15,7+0,4^{b}$ & $15,9+0,3^{b}$ & $16,8+0,4^{\mathrm{ab}}$ & 0,01 \\
\hline $\begin{array}{l}\text { Porcentagem de gordura } \\
\text { Fatpercentage }\end{array}$ & $14,4+08^{b}$ & $17,9+1,2^{\mathrm{a}}$ & $19,2+0,9^{a}$ & $18,7+1,3^{\mathrm{a}}$ & 0,01 \\
\hline $\begin{array}{l}\text { Músculo / osso } \\
\text { Muscle / bone }\end{array}$ & $4,0+0,1$ & $4,3+0,1$ & $4,1+0,1$ & $3,9+0,1$ & 0,09 \\
\hline $\begin{array}{l}\text { Músculo + gordura / osso } \\
\text { Muscle + fat / bone }\end{array}$ & $4,9+0,1 b$ & $5,4+0,2 \mathrm{a}$ & $5,3+0,1 \mathrm{a}$ & $5,0+0,2 \mathrm{ab}$ & 0,01 \\
\hline
\end{tabular}

${ }^{1}$ Escala de 1 a 5 pontos, sendo $3=$ vermelha levemente escura e $4=$ vermelha.

2 Escala de 1 a 5 pontos, sendo $2=$ grosseira, $3=$ levemente grosseira e $4=$ fina.

${ }^{3}$ Escala de 1 a 18 pontos, sendo $4=$ leve menos, $5=$ leve e $6=$ leve mais.

4 Probabilidade.

1 Score from 1 to 5 points, being $3=$ slight dark red and $4=$ red.

2 Score from 1 to 5 points, being $2=$ coarse, $3=$ slightly coarse and $4=$ fine.

${ }^{3}$ Score from 1 to 18 points, being $4=$ slight minus, $5=$ slight and $6=$ slight plus.

4 Probability.

tando, ainda, a importância que o regime alimentar possui na porcentagem de ossos da carcaça. Em trabalho que comparou novilhos com vacas de descarte, Quadros et al. (1990b) observaram maior porcentagem de músculo na carcaça de novilhos $(63,9 \%)$ em relação às vacas de descarte $(58,4 \%)$, ficando as vacas com maior porcentagem de gordura na carcaça $(25,8$ contra 21,4\%). Muller et al. (1990a) constataram que os novilhos Charolês abatidos aos três anos de idade apresentaram maiores porcentagens de músculo e osso na carcaça do que novilhos da mesma raça abatidos um ano mais cedo, os quais foram superiores na porcentagem gordura na carcaça.

Em seu trabalho de pesquisa, Galvão et al. (1991) abateram novilhos de três diferentes estádios de maturidade, verificando que o teor de gordura e músculo na carcaça não diferiu entre os grupos de carcaças avaliados. Restle et al. (2001a) verificaram que o teor de gordura não diferiu entre vacas e novilhas, mas a porcentagem de osso na carcaça foi maior nos animais mais velhos $(15,37 \%)$ do que nas novilhas $(14,46 \%)$.
Apresentam-se na Tabela 5 os resultados referentes às características sensoriais da carne. Observa-se que as fêmeas abatidas aos quatro anos de idade apresentaram carne mais macia que as abatidas aos sete ou oito anos de idade $(\mathrm{P}<0,05)$, mas não diferiram do grupo de vacas abatidas com cinco ou seis e do grupo abatido com mais de oito anos de idade.

Segundo Arthaud et al. (1977), o colágeno, maior responsável pela regulação da maciez da carne (Price \& Schweigert, 1994), pode sofrer variações cíclicas de estabilidade durante o avanço da idade, fazendo com que animais mais velhos possam apresentar carne mais macia que animais mais jovens. Já Muller (1987) acredita que a deposição de gordura na carcaça pode afetar diretamente a maciez da carne de bovinos, entretanto, Vaz (1999) não verificou correlação significativa entre a maciez da carne e as variáveis que expressam a deposição de gordura na carcaça, como o marmoreio e o percentual de gordura.

Revisando diversos trabalhos de pesquisa, Restle et al. (1999) constataram que a carne de animais 
Braford, abatidos com um ano de idade, apresenta maciez média de 6,6 pontos, enquanto os animais da mesma raça, abatidos aos dois anos, apresentaram maciez média de 5,1 pontos. Já na raça Hereford, a diferença é mais acentuada, ou seja, 7,5 e 5,8 pontos, citados na mesma ordem.

Verifica-se, ainda, na Tabela 5, que, embora a maciez da carne medida pelo painel tenha diferido entre os tratamentos, não foi verificada diferença na força de cizalhamento das fibras, a qual é uma medida objetiva que estima com boa precisão a maciez da carne (Price \& Schweigert, 1994). Comparando a qualidade da carne proveniente de novilhos ou vacas de descarte, Muller et al. (1984) observaram força de cizalhamento de 9,21 kg na carne de vacas e 7,08 kg na carne dos novilhos. Já na comparação entre a idade de abate aos dois ou três anos de idade para novilhos, Muller et al. (1990b) observaram que a maciez medida pelo painel de degustadores e a força de cizalhamento das fibras musculares foram semelhantes entre os dois grupos de animais. Da mesma maneira, Restle et al. (2001a) constataram que a força de cizalhamento foi bastante similar entre vacas e novilhas, ou seja, 5,95 e 5,99 kg, respectivamente.

Embora tenham observado semelhança na maciez da carne de novilhos com dois ou três anos de idade,
Muller et al. (1990b) comentam que os animais mais jovens apresentaram carne de melhor suculência e palatabilidade. Também comparando as idades de abate de dois ou três anos para novilhos, o painel de degustadores do trabalho de Townsend et al. (1990a) não mostrou diferença na suculência ou na palatabilidade da carne dos dois grupos de animais. Já Quadros et al. (1990a) constataram que, na comparação entre novilhos e vacas de descarte da raça Hereford, terminados em confinamento, a carne dos primeiros foi significativamente mais suculenta e palatável que das fêmeas de descarte.

As perdas durante o descongelamento e à cocção da carne também foram semelhantes entre as quatro classes de idade $(\mathrm{P}>0,05)$. Muller \& Robaina (1981) salientam, em sua pesquisa, que as perdas durante o descongelamento e a cocção da carne em animais mais velhos são minimizadas quando as carcaças possuem bom acabamento. Os mesmos autores salientam que não só o acabamento é importante, mas também o marmoreio da carne está correlacionado com as perdas durante o preparo da carne. Trabalhando com novilhos Charolês, Townsend et al.(1990a) verificaram que a quebra durante o descongelamento foi superior nos animais abatidos aos dois anos $(6,4 \%)$ em relação àqueles abatidos aos três anos de idade (4,5\%). Também na comparação entre vacas de

Tabela 5 - Média e desvio-padrão para características sensoriais, força de cizalhamento (FC) e quebras durante o descongelamento (QD) e cocção da carne de vacas de descarte de diferentes idades de abate (IA)

Table 5 - Mean and standard deviation for sensorial characteristics, shear force and losses during thawing and cooking of meat of cull cows of different slaughter ages (IA)

\begin{tabular}{|c|c|c|c|c|c|}
\hline \multirow[t]{2}{*}{$\begin{array}{l}\text { Característica } \\
\text { Characteristic }\end{array}$} & \multicolumn{4}{|c|}{$\begin{array}{c}\text { Idade da vaca (anos) } \\
\text { Cow age (years) }\end{array}$} & \multirow[t]{2}{*}{$\overline{\mathrm{P}^{2}}$} \\
\hline & IA4 & IA5-6 & IA7-8 & $\mathrm{IA}+8$ & \\
\hline $\begin{array}{l}\text { Maciez, pontos }{ }^{1} \\
\text { Tenderness, points } 1\end{array}$ & $5,92+0,27^{\mathrm{a}}$ & $5,24+0,39^{\mathrm{ab}}$ & $4,69+0,30^{b}$ & $5,37+0,42^{\mathrm{ab}}$ & 0,05 \\
\hline $\begin{array}{l}\text { Suculência, pontos }{ }^{1} \\
\text { Juiciness, points }{ }^{1}\end{array}$ & $5,74+0,31$ & $5,92+0,44$ & $5,69+0,34$ & $6,15+0,47$ & 0,94 \\
\hline $\begin{array}{l}\text { Palatabilidade, pontos }{ }^{1} \\
\text { Flavor, points } 1\end{array}$ & $5,72+0,21$ & $5,77+0,30$ & $5,78+0,23$ & $6,49+0,32$ & 0,43 \\
\hline $\begin{array}{l}\mathrm{FC}, \mathrm{kg} \\
\text { Shear force, } \mathrm{kg}\end{array}$ & $5,48+0,42$ & $6,74+0,60$ & $6,17+0,46$ & $5,54+0,64$ & 0,55 \\
\hline $\begin{array}{l}\text { QD, \% } \\
\text { Thawing loss, \% }\end{array}$ & $6,6+1,5$ & $7,3+2,1$ & $10,2+1,6$ & $6,1+2,3$ & 0,26 \\
\hline $\begin{array}{l}\text { Quebra à cocção, \% } \\
\text { Cooking loss, \% }\end{array}$ & $29,5+2,1$ & $29,0+3,0$ & $25,0+2,3$ & $28,2+3,2$ & 0,45 \\
\hline
\end{tabular}

\footnotetext{
${ }^{1}$ Escala de 1 a 9 pontos, sendo 1 = extremamente dura, sem suculência e sem sabor, e 9 = extremamente macia, extremamente suculenta e extremamente saborosa.

2 Probabilidade.

${ }^{1}$ Score from 1 to 9 points, being 1 = extremely tough, dry, undesirable and $9=$ extremely tender, juicy and flavorful.

2 Probability.
} 
descarte e novilhos de 2,5 anos, Townsend et al. (1990b) verificaram que os animais mais jovens apresentaram maiores perdas durante o descongelamento ( 7,7 contra $4,9 \%)$.

\section{Conclusões}

A utilização de diferentes níveis de suplemento energético, durante a terminação de vacas de descarte Charolês em pastagem cultivada de estação fria, não afetou as características de qualidade da carcaça e da carne.

Vacas mais velhas apresentaram menor porcentagem de músculo e maior teor de gordura que vacas mais jovens.

Vacas jovens apresentaram carne mais macia do que vacas abatidas aos sete ou oito anos de idade, mas as demais características da carne não diferiram com a idade da vaca ao abate.

\section{Literatura Citada}

ARTHAUD, V.H.; MANDIGO, R.W.; KOCH, R.M. et al. Carcass composition, quality and palatability attributes of bulls and steers feed different energy levels and killed at four ages. Journal of Animal Science, v.44 n.1, p.53-64, 1977.

ANUALPEC. Anuário da pecuária brasileira. São Paulo: Argos, 2000. 392p.

BERG, R.T.; BUTTERFIELD, R.M. New concepts of cattle growth. Sydney: Sydney University Press, 1976. 240p.

CROUSE, J.D.; CALKINS, C.R.; SEIDEMAN, S.C. The effects of rate of change in body weight on tissue development and meat quality of youthful bulls. Journal of Animal Science, v.63, n.7, p.1824-1829, 1986.

DEL DUCA, L.O.; MORAES, C.O.C.; SALOMONI, E. Efeito do peso de abate nas características quantitativas da carcaça de novilhos Ibagé. In: REUNIÃO ANUAL DA SOCIEDADE BRASILEIRA DE ZOOTECNIA, 36., 1999, Porto Alegre. Anais... Porto Alegre: Sociedade Brasileira de Zootecnia, 1999. p.357

DI MARCO, O.N. Crecimiento y respuesta animal. Balcarce: Asociación Argentina de Producción Animal. 1994. 129p.

EUCLIDES FILHO, K.; EUCLIDES, V.P.B.; FIGUEIREDO, G.R. et al. Efeito da suplementação com concentrado sobre características de carcaça de bovinos Nelore. In: REUNIÃO ANUAL DA SOCIEDADE BRASILEIRA DE ZOOTECNIA, 34., 1997, Juiz de Fora. Anais... Juiz de Fora: Sociedade Brasileira de Zootecnia, 1997. p.326-328.

FEIJÓ, G.L.D.; THIAGO, L.R.L.S.; ARRUDA, E.F. Efeito de níveis de concentrado na engorda de bovinos confinados. Características das carcaças de animais Nelore. In: REUNIÃO ANUAL DA SOCIEDADE BRASILEIRA DE ZOOTECNIA, 33., 1996, Fortaleza. Anais... Fortaleza: Sociedade Brasileira de Zootecnia, 1996a. p.76-78.

FEIJÓ, G.L.D.; SILVA, J.M.; THIAGO, L.R.L.S. et al. Efeito de níveis de concentrado na engorda de bovinos confinados. Características das carcaças de animais F1 Pardo Suiço x Nelore. In: REUNIÃO ANUAL DA SOCIEDADE BRASI-
LEIRA DE ZOOTECNIA, 33., 1996, Fortaleza. Anais... Fortaleza: Sociedade Brasileira de Zootecnia, 1996b. p.79-81.

FEIJÓ, G.L.D.; SILVA, J.M.; THIAGO, L.R.L.S. et al. Produção e qualidade da carne de vacas de descarte. Características das carcaças de vacas em confinamento sob diferentes níveis de concentrado. In: REUNIÃO ANUAL DA SOCIEDADE BRASILEIRA DE ZOOTECNIA, 37., 2000, Viçosa. Anais... Viçosa: Sociedade Brasileira de Zootecnia, 2000, p.476.

GALVÃO, J.G.; FONTES, C.A.A.; PIRES, C.C. Características e composição física da carcaça de bovinos não-castrados, abatidos em três estágios de maturidade (Estudo II) de três grupos raciais. Revista da Sociedade Brasileira de Zootecnia, v.20, n.5, p.503-512, 1991.

HANKINS, O.G.; HOWE, P.E. Estimation of the composition of beef carcasses and cuts. Washington: United States Department of Agriculture, 1946. (Technical Bulletin, 926).

KROPF, D.H.; GRAFF, R.L. The effect of carcass grade, weight and classification upon boneless beef yield. Journal of Animal Science, v.18, n.1, p.95-103, 1959.

MOTT, G.O.; LUCAS, H.L. The design conduction and interpretation of grazing trials on cultivated and improved pastures. In: INTERNATIONAL GRASSLAND CONGRESS, 6., 1952, Pennsylvania. Proceedings... Pennsylvania: State College Press, 1952. p.1380-1395.

MULLER, L.; AGUIRRE, L.F.; RESTLE, J. et al. Parâmetros quantitativos em carcaças de bovinos submetidos a dois regimes alimentares durante o inverno. In: REUNIÃO ANUAL DA SOCIEDADE BRASILEIRA DE ZOOTECNIA, 27. 1990, Campinas. Anais... Campinas: Sociedade Brasileira de Zootecnia, 1990a, p.356.

MULLER, L.; AGUIRRE, L.F.; RESTLE, J. et al. Parâmetros qualitativos da carne de bovinos submetidos a dois regimes alimentares durante o inverno. In: REUNIÃO ANUAL DA SOCIEDADE BRASILEIRA DE ZOOTECNIA, 27., 1990, Campinas. Anais... Campinas: Sociedade Brasileira de Zootecnia, 1990b. p.355.

MULLER, L.; GRASSI, C.; RESTLE, J. Comparação da qualidade da carcaça proveniente de novilhos e vacas. In: REUNIÃO ANUAL DA SOCIEDADE BRASILEIRA DE ZOOTECNIA, 21., 1984, Belo Horizonte. Anais... Belo Horizonte: Sociedade Brasileira de Zootecnia, 1984. p.107.

MULLER, L. Normas para avaliação de carcaças e concurso de carcaça de novilhos. 2.ed. Santa Maria: Universidade Federal de Santa Maria, 1987. 31p.

MULLER, L.; PRIMO, A.T. Influência do regime alimentar no crescimento e terminação de bovinos e na qualidade da carcaça. Pesquisa Agropecuária Brasileira, v.21, n.4, p.445-452, 1986.

MULLER, L.; ROBAINA, G.P. Qualidade da carne de novilhos de raças britânicas de idade cronológica diferentes. In: REUNIÃO ANUAL SOCIEDADE BRASILEIRA DE ZOOTECNIA, 18., 1981, Goiânia. Anais... Goiânia: Sociedade Brasileira de Zootecnia, 1981. p.391.

PASCOAL, L.L.; RESTLE, J.; ROSO, C. Desempenho e economicidade da suplementação em pastagem. In: RESTLE, J. (Ed.) Confinamento, pastagens e suplementação para produção de bovinos de corte. Santa Maria: Universidade Federal de Santa Maria, 1999. p.62-84.

PASCOAL, L.L.; VAZ, F.N.; RESTLE, J. et al. Qualidade da carne e da carcaça de novilhos Braford, terminados aos quatorze meses, com diferentes níveis de concentrado. In: REUNIÃO ANUAL DA SOCIEDADE BRASILEIRA DE 
ZOOTECNIA, 35., 1998, Botucatu. Anais... Botucatu: Sociedade Brasileira de Zootecnia, 1998. p.134-136.

PEROBELLI, Z.V.; MULLER, L.; RESTLE, J. Estudo da qualidade das carcaças e da carne de vacas de descarte de dois grupos genéticos. Ciência Rural, v.24, n.3 p.613-616, 1994.

PRICE, J.F.; SCHWEIGERT, B.S Ciencia de la carne y de los productos carnicos. 2.ed. Zaragoza: Acribia, 1994. 581p.

QUADROS, A.R.B.; RESTLE, J.; BONECARRERE SANCHEZ, L.M. et al. Características qualitativas de carcaças e da carne de novilhos e vacas alimentadas com diferentes fontes protéicas. In: REUNIÃO ANUAL SOCIEDADE BRASILEIRA DE ZOOTECNIA, 27., 1990, Campinas. Anais... Campinas: Sociedade Brasileira de Zootecnia, 1990a. p.23.

QUADROS, A.R.B.; RESTLE, J.; BONECARRERE SANCHEZ, L.M. et al. Características quantitativas de carcaça de novilhos e vacas alimentados com diferentes fontes protéicas. In: REUNIÃO ANUAL SOCIEDADE BRASILEIRA DE ZOOTECNIA, 27., 1990, Campinas. Anais... Campinas: Sociedade Brasileira de Zootecnia, 1990b. p.24.

RESTLE, J.; KEPLIN, L.A.S.; VAZ, F.N. et al. Qualidade da carne de novilhos Charolês confinados e abatidos com diferentes pesos. Ciência Rural, v.26, n.3, p.463-466, 1996.

RESTLE, J.; LUPATINI, G.C.; ROSO, C. et al. Eficiência e desempenho de categorias de bovinos de corte em pastagem cultivada. Revista Brasileira de Zootecnia, v.27, n.2, p.397-404, 1998.

RESTLE, J. Confinamento, pastagens e suplementação para produção de bovinos de corte. Santa Maria: Universidade Federal de Santa Maria, 1999. 259p.

RESTLE, J.; BRONDANI, I.L.; BERNARDES, R.A.C. O novilho superprecoce. In: RESTLE, J. (Ed.) Confinamento, pastagens e suplementação para produção de bovinos de corte. Santa Maria: Universidade Federal de Santa Maria, 1999. p.191-214.

RESTLE, J.; EIFERT, E.C.; VAZ, F.N. Características da carcaça de novilhos terminados com diferentes níveis de concentrado. In: REUNIÃO ANUAL DA SOCIEDADE BRASILEIRA DE ZOOTECNIA, 37., 2000, Viçosa. Anais... Viçosa: SBZ, 2000a. p.353.

RESTLE, J.; VAZ, F.N.; ALVES FILHO, D.C. et al. Suplementação energética para vacas de descarte de diferentes idades em terminação em pastagem cultivada de estação fria sob pastejo horário. Revista Brasileira de Zootecnia, v.29, n.4, p.1216-1222, 2000b.

RESTLE, J.; VAZ, F.N.; ALVES FILHO, D.C. et al. Características quantitativas da carcaça de novilhas ou vacas de descarte Charolês, terminadas em confinamento. In: REUNIÃO ANUAL DA SOCIEDADE BRASILEIRA DE ZOOTECNIA, 37., 2000, Viçosa. Anais... Viçosa: Sociedade Brasileira de Zootecnia, 2000c. p.146.

RESTLE, J.; CERDÓTES, L.; VAZ, F.N. Características da carcaça e da carne de novilhas e vacas de descarte Charolês, terminadas em confinamento. Revista Brasileira de Zootecnia, v.30, n.3 (Supl.1), p.1065-1075, 2001a.
RESTLE, J.; VAZ, F.N.; ROSO, C. et al. Desempenho e características da carcaça de vacas de diferentes grupos genéticos em pastagem cultivada com suplementação energética. Revista Brasileira de Zootecnia, v.30, n.6, p.1813-1823, $2001 \mathrm{~b}$.

ROCHA, J.B.T.; PEROTTONI, J.; RESTLE, J. et al. Qualidade da carne de animais inteiros de dois grupos genéticos, abatidos aos quatorze meses de idade. In: REUNIÃO ANUAL DA SOCIEDADE BRASILEIRA DE ZOOTECNIA, 34., 1997, Juiz de Fora. Anais... Juiz de Fora: Sociedade Brasileira de Zootecnia, 1997. p.199-201.

SAS INSTITUTE. SAS language reference. Version 6, Cary: 1990. $1042 p$.

TOWNSEND, M.R.; RESTLE, J.; MULLER, L. Avaliação qualitativa de carcaças de novilhos com diferentes idades confinados por dois invernos subsequentes. In: REUNIÃO ANUAL SOCIEDADE BRASILEIRA DE ZOOTECNIA, 27., 1990, Campinas. Anais... Campinas: SBZ, 1990a. p.359.

TOWNSEND, M.R.; RESTLE, J.; PASCOAL, L.L. et al. Características qualitativas das carcaças de novilhos e vacas terminadas em confinamento. In: REUNIÃO ANUAL SOCIEDADE BRASILEIRA DE ZOOTECNIA, 27., 1990, Campinas. Anais... Campinas: Sociedade Brasileira de Zootecnia, 1990b. p.361.

VAZ, F.N. Cruzamento alternado das raças Charolês e Nelore: características de carcaça e da carne de novilhos abatidos aos dois anos. Santa Maria: Universidade Federal de Santa Maria, 1999, 58p. Dissertação (Mestrado em Zootecnia) - Universidade Federal de Santa Maria, 1999.

VAZ, F.N.; RESTLE, J. Produção de carne com qualidade. In: RESTLE, J.; BRONDANI, I.L.; PASCOAL, L.L. et al. (Eds.) Produção intensiva com qualidade em bovinos de corte, Santa Maria: Universidade Federal de Santa Maria, 1998. p.104-119.

ZERVOUDAKIS, J.T.; PAULINO, M.F.; DETMANN, E. Características de carcaça de bovinos mestiços suplementados no período das águas. In: REUNIÃO ANUAL DA SOCIEDADE BRASILEIRA DE ZOOTECNIA, 37., 2000. Viçosa, MG. Anais... Viçosa: Sociedade Brasileira de Zootecnia, 2000. p.355. 